\title{
A STUDY OF POSTOPERATIVE WOUND INFECTION AMONG POST SURGICAL PATIENTS AT CALICUT MEDICAL COLLEGE, KERALA, INDIA
}

Prasanna Gupta ${ }^{1}$.

\section{Assistant Professor, Department of Microbiology, Konaseema Institute of Medical Sciences, Amalapuram,} Andhra Pradesh, India.

\section{CORRESPONDING AUTHOR}

Dr. Prasanna Gupta ${ }^{1}$, Dept. of Microbiology,

Konaseema Institute of Medical Sciences,

Amalapuram- 533201, Andhra Pradesh, India,

E-mail: pramin1414@yahoo.co.in,

Ph: 00919630238572.

ABSTRACT: BACKGROUND: Postoperative wound infections or surgical site infections (SSIs) are associated with increased morbidity and mortality as they can cause delay in recovery, increase length of stay and increased health care costs. This study was conducted to find out the prevalence and sensitivity pattern of surgical site infections among post surgical cases at Calicut Medical College. METHODOLOGY: The study was conducted for a period of one year from July 2007 to June 2008. Two swabs were collected from each site. One swab was used for direct smear examination after Gram staining and second swab was subjected to culture and antibiotic sensitivity testing by standard microbiological techniques. RESULTS: The total numbers of surgeries done during the one year period in three surgical units were 1902. The number of clinically suspected cases was 102 (5.36\%). The study included 27 'clean', 32 'cleancontaminated' , 13 'contaminated' and 30 'dirty' cases. Culture proven cases were 36 out of 102. Lowest infection rate was seen in clean $(18.5 \%)$ surgery followed by clean-contaminated (37.5\%), contaminated (38.5\%) and dirty surgeries (47\%). MRSA (Methicillin resistant Staphylococcus aureus) (83\%) and multidrug resistant gram negative bacilli were predominant isolates. Alarming rate of resistance to ciprofloxacin, cefazolin, ceftriaxone and ampicillin were observed. CONCLUSION: The commonly used antibiotics for empiric treatment of post operative wound infections may not be effective. Development of a suitable antibiotic policy and surveillance is essential to reduce the postoperative wound infection rates.

KEY WORDS: surgical site infections; antibiotic susceptibility; India

INTRODUCTION: Postoperative wound infections or surgical site infections (SSIs) are associated with increased morbidity and mortality as they can cause delay in recovery, increase length of stay, increase health care costs by delaying discharge with associated increase in the need for investigations, treatment and nursing care.

Low rate of SSIs are directly related to education, awareness of the cause of infection and the introduction of practices that reduce risk. ${ }^{1}$ According to WHO report 2002, prevalence rate of health care associated infection (HCAI) is 7.7\% - 9\% in developed countries and 10$11.8 \%$ in developing countries. The common HCAI as per CDC update 2007 is UTI (32\%) followed by postoperative wound infections (22\%), nosocomial pneumonia (15\%) and nosocomial septicemia (14\%). ${ }^{2}$ Causative organisms of post operative wound infections are Staphylococcus aureus and Streptococcus pyogenes in clean surgery. E. coli, Klebsiella species, Pseudomonas species, Acinetobacter species, Staphylococcus aureus and Streptococcus species 
are usually found in abdominal and gynaecological surgeries. E. coli, Proteus species, Klebsiella species, Pseudomonas species and Acinetobacter species are associated with urological surgeries. Orthopedic surgeries commonly have infections with Staphylococcus aureus and Gram negative bacilli according to the data from the National Nosocomial infections surveillance system of the centres for disease control and prevention $2007(C D C)^{3}$.

So we planned to study the prevalence, bacteriological profile and susceptibility pattern of SSI associated pathogens in our hospital.

MATERIALS AND METHODS: The study was conducted in the Department of Microbiology, Medical College, Calicut for a period of one year from July 2007 to June 2008. Patients from three surgical units S1, S3 and S5 were subjected to the study. The total number of elective and emergency surgeries done during the one year period in the above three units was 1902, which included 1074 elective (major) and 828 emergency cases. One hundred and two cases of clinically suspected postoperative wound infection (Fifty nine elective and fourty three emergency) from the above cases were studied in detail. The study included twenty seven 'clean', thirty two 'clean-contaminated' , thirteen 'contaminated' and thirty 'dirty' cases. Samples were collected from patients using two sterile cotton swabs. One swab was used for direct smear examination after Gram staining. The second swab was subjected to culture and antibiotic sensitivity testing of the isolates by Stokes method for Staphylococcus species and Kirby Bauer method for Gram negative bacilli. The following antibiotic discs were used for sensitivity testing of Gram positive cocci: Penicillin (10 units), Erythromycin (15mcg), Gentamycin $(10 \mathrm{mcg})$, Vancomycin(30 mcg), Cefazolin(30 mcg). Oxacillin screen agar was used for Staphylococcus species to rule out MRSA. For Gram negative bacilli Ampicillin (10 mcg), Gentamycin (10 mcg), Cefazolin (30 mcg), Ceftriaxone (30mcg), Amikacin (30 mcg) and Ciprofloxacin $(5 \mathrm{mcg}$ ) were used for sensitivity testing. For Pseudomonas species Ceftazidime ( $30 \mathrm{mcg})$ was also besides above mentioned antibiotics.

RESULTS: The overall prevalence of postoperative wound infections was 5.36\% (102). Among 102 clinically suspected cases studied, bacteriologically proven surgical site infection was identified in 36 patients. The prevalence of culture positive infections was 35\% (36/102) (Table1). Lowest culture positivity rate was seen in clean surgery $(18.5 \%)$ followed by cleancontaminated $(37.5 \%)$, contaminated $(38.5 \%)$ and dirty surgeries $(47 \%)$.

Table 1: Prevalence of infections in various types of surgeries $(n=102)$

\begin{tabular}{|l|l|c|c|c|}
\hline & $\begin{array}{l}\text { Category of } \\
\text { surgery }\end{array}$ & $\begin{array}{l}\text { No. of clinically } \\
\text { suspected cases }\end{array}$ & $\begin{array}{l}\text { No. of cases with } \\
\text { proven infection }\end{array}$ & $\begin{array}{l}\text { Prevalence of } \\
\text { infection (\%) }\end{array}$ \\
\hline A & Clean & 27 & 5 & 18.5 \\
\hline B & $\begin{array}{l}\text { Clean- } \\
\text { contaminated }\end{array}$ & 32 & 12 & 37.5 \\
\hline C & Contaminated & 13 & 5 & 38.5 \\
\hline D & Dirty & 30 & 14 & 47 \\
\hline
\end{tabular}

Journal of Evolution of Medical and Dental Sciences/Volume1/ Issue4/October - 2012 Page 583 
Staphylococcus aureus was isolated from 18 cases, Escherichia coli from 15 cases and Enterobacter species from 2 cases. Klebsiella pneumoniae, Acinetobacter spp. and Serratia marcescens was isolated from one case each. Pseudomonas aeruginosa was isolated from 4 cases (Table 2).

Table 2: Organisms isolated from infected wounds $(n=42)$

\begin{tabular}{|l|c|c|}
\hline Organisms & No. of isolates & \% of isolation \\
\hline Staphylococcus aureus & 18 & 43 \\
\hline Escherichia Coli & 15 & 36 \\
\hline Pseudomonas aeruginosa & 4 & 9.5 \\
\hline Klebsiella Oxytoca & 1 & 2.3 \\
\hline Enterobacter kobei & 1 & 2.3 \\
\hline Enterobacter intermedius & 1 & 2.3 \\
\hline Acinetobacter baumannii & 1 & 2.3 \\
\hline Serratia marcescens & 1 & 2.3 \\
\hline
\end{tabular}

Out of 18 isolates of Staphylococcus aureus none were sensitive to penicillin and erythromycin. All isolates were sensitive to vancomycin. Fifteen isolates of S. aureus were found to be MRSA (Methicillin resistant Staphylococcus aureus). Of the total 24 gram negative bacterial isolates none were sensitive to Ampicillin. Interestingly 22 of these gram negative isolates were multi drug resistant (92\%). Amongst Gram negative isolates fifteen were Escherichia coli. All the strains were resistant to ampicillin, cefazolin, ceftriaxone and ciprofloxacin. Amikacin had a sensitivity of 73.3\% (Table 3). Figure 1 and 2 depicts prevalence of post operative wound infections.

Table 3: Susceptibility pattern of the isolates in percentage $(n=42)$

\begin{tabular}{|l|l|l|l|l|l|l|l|}
\hline ANTIBIOTIC & $\begin{array}{l}\text { S. } \\
\text { aureus } \\
\mathbf{( 1 8 )}\end{array}$ & $\begin{array}{l}\text { E.Coli } \\
\mathbf{( 1 5 )}\end{array}$ & $\begin{array}{l}\text { Enterobac } \\
\text { ter spp. } \\
\mathbf{( 2 )}\end{array}$ & $\begin{array}{l}\text { Pseudom } \\
\text { onas } \\
\text { aerugino } \\
\text { sa } \\
\mathbf{( 4 )}\end{array}$ & $\begin{array}{l}\text { Klebs } \\
\text { iella } \\
\text { spp. } \\
\mathbf{( 1 )}\end{array}$ & $\begin{array}{l}\text { Serratia } \\
\text { marcesce } \\
\text { ns } \\
\mathbf{( 1 )}\end{array}$ & $\begin{array}{l}\text { Acinetobact } \\
\text { er spp. } \\
\mathbf{( 1 )}\end{array}$ \\
\hline Penicillin & Nil & NT & NT & NT & NT & NT & NT \\
\hline Erythromycin & Nil & NT & NT & NT & NT & NT & NT \\
\hline Gentamicin & 22.2 & 13.3 & Nil & 25 & 100 & Nil & 100 \\
\hline Ampicillin & NT & Nil & Nil & NT & Nil & Nil & Nil \\
\hline Vancomycin & 100 & NT & NT & NT & NT & NT & NT \\
\hline Cefazolin & 22.2 & Nil & Nil & Nil & Nil & Nil & 100 \\
\hline Ceftazidime & NT & NT & NT & 25 & NT & NT & NT \\
\hline Oxacillin & 27.7 & NT & NT & NT & NT & NT & NT \\
\hline Piperacillin & NT & NT & NT & 25 & NT & NT & NT \\
\hline Amikacin & NT & 73.3 & 100 & 25 & 100 & Nil & 100 \\
\hline Ciprofloxacin & NT & Nil & 50 & 25 & Nil & Nil & 100 \\
\hline Ceftriaxone & NT & Nil & Nil & NT & Nil & Nil & 100 \\
\hline
\end{tabular}

Abbreviations: NT - Not tested 
Table 4: Preoperative hospital stay and infection rate $(n=102)$

\begin{tabular}{|l|l|l|l|}
\hline $\begin{array}{l}\text { Period of } \\
\text { preoperative hospital } \\
\text { stay }\end{array}$ & No.of cases & $\begin{array}{l}\text { No.of infected } \\
\text { cases }\end{array}$ & \% of infection \\
\hline $1-3$ days & 61 & 18 & 29.5 \\
\hline $4-7$ days & 16 & 5 & 31.2 \\
\hline $7-14$ days & 15 & 7 & 43.7 \\
\hline$>14$ days & 10 & 6 & 60 \\
\hline Total & 102 & 36 & 35 \\
\hline
\end{tabular}

Table 5: Age of the patient $\&$ infection rate $(n=102)$

\begin{tabular}{|l|l|l|l|}
\hline Age group & No.of patients & $\begin{array}{l}\text { No.of infection } \\
\text { cases }\end{array}$ & Percentage \\
\hline $15-25$ & 20 & 4 & 20 \\
\hline $26-35$ & 14 & 4 & 28.5 \\
\hline $36-45$ & 13 & 4 & 30.7 \\
\hline $46-55$ & 20 & 7 & 35 \\
\hline $56-65$ & 19 & 8 & 42.1 \\
\hline $66-75$ & 10 & 5 & 50 \\
\hline $76-85$ & 6 & 4 & 67 \\
\hline Total & 102 & 36 & 35 \\
\hline
\end{tabular}

Table 6: Sex wise distribution of the patients with wound infection $(n=102)$

\begin{tabular}{|l|l|l|l|}
\hline No. of patients & Sex & No. of infection cases & Percentage \\
\hline 70 & Male & 25 & 36 \\
\hline 32 & Female & 11 & 34.3 \\
\hline 102 & Total & 36 & 35 \\
\hline
\end{tabular}

Fig.1: Prevalence of postoperative wound infection in the study group

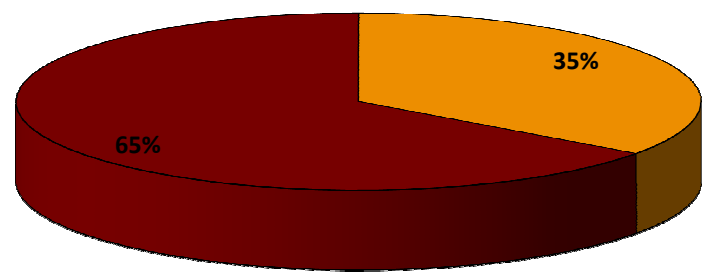

口Infection aNo infection 
Fig: 2 prevalence of postoperative wound infection in different types of surgery

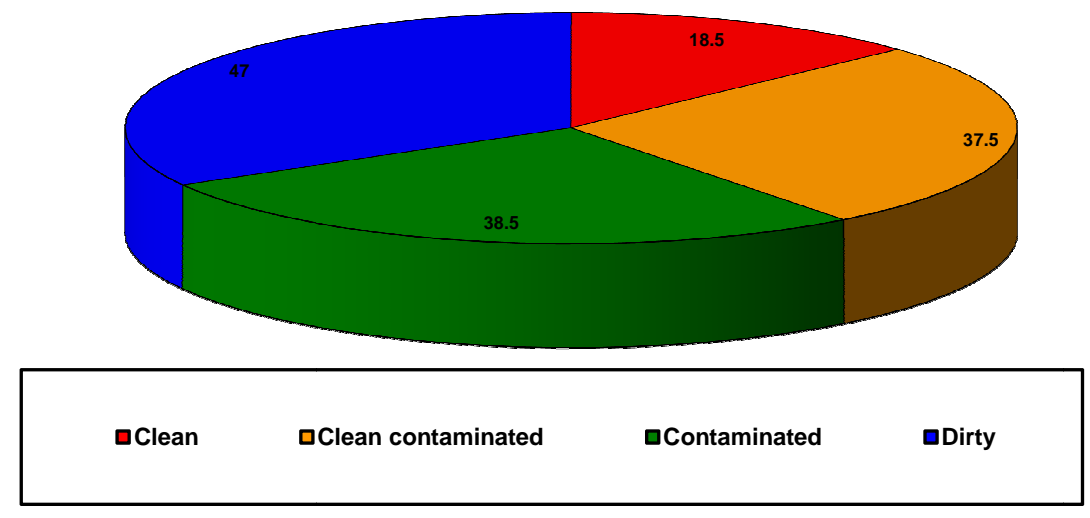

Fig.3: Organisms isolated from infected wounds

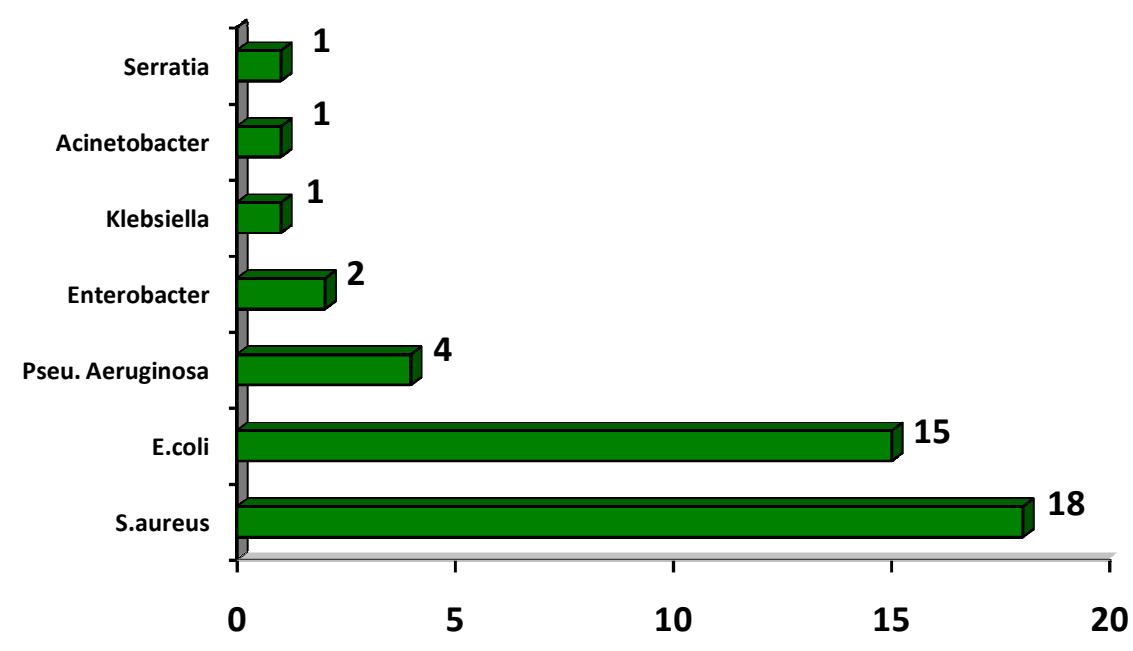

DISCUSSION: Charles D Ericsson also reports a rate of 1\% for clean surgeries and 5 to $10 \%$ for 'clean-contaminated' cases. ${ }^{4}$ An overall infection rate of $4.53 \%$ is reported by Yalcin et al in his study conducted at Cumhuriyet University Medicine Faculty Hospital in Turkey between January 1992 and December $1993 .^{5}$ According to a study the incidence of SSIs with regard to abdominal surgical sites and operating conditions for clean wounds is $1.5-3.7 \%$, clean contaminated is $3-4 \%$, contaminated is $8.5 \%$ and dirty-infected wounds is $28-40 \%{ }^{6}$

The reported overall infection rates of postoperative wound infections from various centers show wide variation..$^{7-9} \mathrm{~A}$ prolonged preoperative hospital stay has been identified as an important risk factor in infection by many authors like Shanson, Timothy D Jacob and Yalcin et al. It promotes acquisition of multidrug resistant hospital strains.5, 10,11. The results of this study 
shows a high infection rate in association with a prolonged pre-operative stay in the hospital. (Table-4)

The infection rate of this study also shows an increase with age as observed in many other studies also (Table 5). ${ }^{10,12,13}$ Male sex was identified as one of the risk factors of postoperative wound infection by Velasco E et al 1998 based on the study on 1205 patients over a period of 1 year at National Cancer Institute Hospital Brazil. ${ }^{14}$ In the present study male patients had a slightly higher infection rate (36\%) compared to females (34.3\%)(Table 6).

In this study (eighteen) $43 \%$ of the isolates was Staphylococcus aureus, of which fifteen (83\%) were MRSA. Escherichia coli accounted for fifteen cases (36\%). This was followed by Pseudomonas aeruginosa four (9.5\%), Enterobacter species two (4.6\%), Klebsiella pneumoniae one (2.3\%), Acinetobacter spp. one (2.3\%) (Table 2 and Figure 3). Review of bacteriology of surgical wounds in different features reveal that the results are in accordance with the observations of the present study.10, 15-20 Table 3 explains the susceptibility profile of the isolates. A prospective study of surgical site infections in a teaching hospital in Goa reported $79 \%$ of isolates were Gram negative and almost 64\% demonstrated a high degree of antimicrobial resistance. ${ }^{20}$ High degree of drug resistance was observed against ciprofloxacin, cefazolin, ceftriaxone and ampicillin.

CONCLUSION: The alarming rate of resistance to ciprofloxacin, cefazolin, ceftriaxone and ampicillin for major postoperative wound infections precludes the use of these commonly used antibiotics for empiric treatment of post operative wound infections. The type of surgeries, length of preoperative stay had an important role in determining the pattern of wound infection. Development of a suitable antibiotic policy is essential to reduce the postoperative wound infection rates. Establishment of proper surveillance programme is also essential.

ACKNOWLEDGEMENTS: Funding: None. I would like to express my sincere gratitude to Dr. Beena Philomina J., Associate Professor Department of Microbiology Calicut Medical College, Kerala for her contribution and support during this work and I express my sincere thanks to Dr. Raghuram V. Associate Professor, Community Medicine, KIMS Amalapuram, for his valuable suggestions during preparation of this manuscript.

\section{REFERENCES:}

1. Mangram AJ, Horan TC, Pearson ML et al. Guideline for prevention of surgical site infection. Infect control Hosp Epidemiology 1999; 20: 247-78.

2. Ramani Bai JT. Hospital infection - Present scenario. Proceedings of the fourth triennial conference of the academy of clinical Microbiologists and pre-conference seminar on changing trends in hospital infections.August 22nd \& 23rd 2008 (18-23)

3. National nosocomial infections surveillance system, Centers for disease control and prevention (CDC) Health care associated infection (HCAI) updated 2007.

4. Ericsson CD and Rowlands BJ. Surgical infection: Principles and management of antibiotic usage. Physiologic basis of modern surgical care. 1988; 113-35.

5. Yalcin AN and Bakir M. Postoperative wound infections. Journal of Hospital Infection 1995; Apr 29(4): 305-9.

6. Abdominal surgical site infections : incidence and risk factors at an Iranian teaching hospital . Seyd Mansour Razavi, Mohammad Ibrahimpoor , Ahmad Sabouri Kashani and 
Ali Jafarian BMC Surgery 2005 , 5:2 online at www. Biomed central .com/1471$2482 / 5 / 2$

7. Kotisso B and Aseffa A. Surgical wound infection in a teaching hospital in Ethiokia. East African Medical Journal. 1998 Jul; 75(7): 402-5.

8. Salemi C, Anderson D and Flores D. Surgical site infection risk index rates. Infect control Hosp. Epidemiol 1997 Apr; 18(4): 246-7.

9. Antos KR, Fonseca LS, Bravo Neto GP and Gotijo Filho PP. Surgical site infection: rates, etiology and resistance patterns of antimicrobials among strains isolated at Rio De Janeiro University Hospital. Infection 1997 Jul-Aug; 25(4): 217-20.

10. Jacob DT, Richard L and Simmons. Preoperative antimicrobial prophylaxis. Master of surgery. 1998; $3^{\text {rd }}$ edition, Vol.1; 134-45.

11. Shanson DC. Hospital Infection. Microbiology in clinical practice 1999; $3^{\text {rd }}$ Edition: 42958.

12. Gregory WJ and MeNabb PC. Pseudomonas cepacia. Infection control 1986 May; 7(5): 281-4.

13. Shirahatti RG, Joshi RM, Vishwanath YK, Shinkren et al. Effect of preoperative skin preparation on postoperative wound infection. J Postgrad Med 1993 Jul-Sept; 39(3): 134-6.

14. Velasco E, Thuler LC, Martins CA et al. Risk index for prediction of surgical site infection after oncology operations. Am J Infect Control 1998 Jun; 26(3): 217-23.

15. Topley and Wilson's microbiology and microbial infection. Hospital - acquired infection. 1998; Vol.3: 9th edn. 187-219.

16. Forrest APM, Carter DC and Cleod. Infections and Antibiotics. Principles and practice of surgery. 1995. $3^{\text {rd }}$ edn, 67-83.

17. Saha SC, Zaman MA, Khan MR and Ali SM. Common aerobic bacteria in postoperative wound infection and their sensitivity pattern. Bangladesh Med Res Counc Bull 1995 Apr; 21(1): 32-7.

18. Urschel JD. Necrotizing soft tissue infections. Post graduate Medical J 1999 Nov; 75(889): 645-9.

19. Giacometti A and Cirionio. Epidemiology and Microbiology of surgical wound infections. J of Clin Microbiology 2000 Feb; 38(2): 918-22.

20. Umesh S. Kamat, A.M.A.Fereirra, M.S.Kulkarni, D.D.Motghare. A prospective study of surgical site infections in a teaching hospital in Goa. Indian J. Surg.(May june2008)70:120-124 